\title{
Treatment of patients with von Willebrand disease
}

\author{
Emma Tuohy' \\ Emma Litt' \\ Raza Alikhan ${ }^{1,2}$ \\ 'Department of Haematology, \\ University Hospital of Wales, Cardiff, \\ UK; ${ }^{2} \mathrm{Haemophilia}$ and Thrombosis \\ Centre, University Hospital of Wales, \\ Cardiff, UK
}

This article was published in the following Dove Press journal: Journal of Blood Medicine 20 April 20II

Number of times this article has been viewed

Abstract: Von Willebrand disease (vWD) is the most common hereditary bleeding disorder. The aim of therapy is to correct the dual hemostatic defect, due to defective platelet adhesionaggregation and abnormal coagulation due to Factor VIII (FVIII) deficiency. The choice of treatment depends on a number of factors, including the severity of the bleed, the procedure planned, the subtype and severity of the disease and the age and morbidity of the patient. Desmopressin (DDAVP) is the treatment of choice for type $1 \mathrm{vWD}$ as it increases endogenous release of FVIII and von Willebrand factor (VWF) and is also used in some subtypes of type 2 vWD. In those patients in whom DDAVP is ineffective or contraindicated, levels can be restored by infusing vWF:FVIII concentrates. The role of antifibrinolytic treatment is an important adjunct to replacement therapy during minor or major surgery involving mucosal surfaces. The dosing and timing of vWF:FVIII concentrates is important depending on the nature of the surgical procedure. The role of secondary prophylaxis needs to be further defined.

Keywords: von Willebrand disease, treatment, DDAVP

\section{Introduction}

Von Willebrand disease (vWD) is the commonest congenital bleeding disorder, with a prevalence estimated from population studies of about $1 \% .{ }^{1}$ It is caused by inherited defects in the concentration, structure or function of von Willebrand factor (vWF). vWF has two essential functions:

- Primary hemostasis - vWF enables platelets to adhere to injured vascular endothelium and then to form platelet aggregates.

- Secondary hemostasis - vWF binds to and stabilizes factor VIII (FVIII). In the presence of vWF the half-life of FVIII is $8-12$ hours, in its absence it is $<1$ hour.

The vWF gene is located on the short arm of chromosome 12 (12p13.2). ${ }^{2}$ Mutations in the vWD gene result in quantitative or qualitative defects of vWF. The current classification of vWD is as follows: ${ }^{3,4}$

Quantitative defects:

- Type 1 vWD - partial loss of vWF

- Type 3 vWD - total loss of vWF

Correspondence: Raza Alikhan Haemophilia and Thrombosis Centre University Hospital of Wales Heath Park, Cardiff CFI4 4XW Tel +44292074 4039 Fax +44292074 8266 Email raza.alikhan@wales.nhs.uk

- Type 2A - absence of high molecular weight (HMW) multimers of vWF

- Type 2B - increased affinity of vWF for platelet glycoprotein Ib (GpIb), causing removal of HMW multimers from plasma and associated with thrombocytopenia submit your manuscript | www.dovepress.com

Dovepress

DOI: 10.2147 /]BM.S9890
Journal of Blood Medicine 201 I:2 49-57

(C) 201 I Tuohy et al, publisher and licensee Dove Medical Press Ltd. This is an Open Access article which permits unrestricted noncommercial use, provided the original work is properly cited. 
- Type 2M - defective interaction between vWF and platelets and no loss of HMW multimers

- Type $2 \mathrm{~N}$ - defect in the N-terminal region of vWF where the binding domain for FVIII is located resulting in reduced binding of vWF to FVIII. No loss of HMW multimers.

The aim of therapy in vWD is to correct the dual hemostatic defect, due to defective platelet adhesion-aggregation and abnormal coagulation due to FVIII deficiency. These deficiencies can be corrected by increasing endogenous production of FVIII and vWF function using desmopressin $\left(D_{D A V P}{ }^{\circledR}\right.$ ) or by administration of $v W F$ concentrates. The choice of treatment depends on a number of factors including the nature of the bleed or invasive procedure planned, the subtype and severity of vWD, the duration of treatment, the age of the patient and the previous response to treatment. Other treatments, such as antifibrinolytic agents (eg, tranexamic acid), can be used alone or as an adjunctive treatment, in order to achieve a hemostatic effect, without affecting the vWF levels. This review summarizes our management of patients with vWD based on the literature and our experience.

\section{Desmopressin}

Desmopressin (1-desamino-8-D-arginine vasopressin, DDAVP), a synthetic vasopressin analog, increases endogenous vWF by secreting it from its natural site of synthesis and storage, the vascular endothelial cell. ${ }^{5}$ It can be administered intravenously, ${ }^{6,7}$ subcutaneously ${ }^{8}$ or intranasally. ${ }^{7}$ The intravenous dose is $0.3 \mathrm{mcg} / \mathrm{kg}$ (maximum dose $28 \mathrm{mcg}$ ), given diluted in normal saline over 30 minutes. Treatment can be repeated every 12-24 hours depending on the type or severity of the bleed. Plasma vWF:FVIII levels are increased to 2-4 times above the baseline within 30 minutes and in general high levels last in the plasma for 6-8 hours. ${ }^{11,12}$

DDAVP is a very valuable drug as it avoids exposure to blood products and is a cheaper alternative. The vWD subtype, however affects the decision on whether to use DDAVP or a vWF- containing concentrate. It has been used cautiously in children because of the risk of hyponatremic seizures, although this risk must be balanced against that of exposing a child to a pooled blood product. ${ }^{9}$

DDAVP is usually effective in patients with type $1 \mathrm{vWD}$ and baseline vWF and FVIII levels higher than $10 \mathrm{IU} / \mathrm{dL} .{ }^{10}$ In order to assess the response to DDAVP, a trial should be performed, measuring the FVIII and vWF ristocetin cofactor (vWF:RCo) pre-infusion and 1 hour post-infusion. An additional assay can be performed at 2-4 hours to evaluate for shortened survival of vWF, and should be considered in patients with a poor response to treatment. ${ }^{11}$ In a prospective trial conducted by Castaman et al, complete responses (post-infusion levels of FVIII:C and vWF:RCo of at least $50 \mathrm{IU} / \mathrm{dL}$ ) or partial responses (post-infusion levels of FVIII:C and vWF:RCo less than $50 \mathrm{IU} / \mathrm{dL}$, but at least 3-fold the basal levels) were observed in $84 \%$ and $13 \%$ of the cases, respectively. This was reduced in other sub-types of vWD. ${ }^{12}$

By performing half-life studies, patients with accelerated clearance of vWF and FVIII can be identified, such as those with Vicenza type vWD. This variant of vWD is due to a specific mutation, Arg1205His, which promotes increased clearance of $\mathrm{vWF}$ from the circulation (five times more rapidly than normal). This information could therefore influence treatment. ${ }^{13}$

The response to DDAVP is variable in types $2 \mathrm{~A}$ and $2 \mathrm{M}$ and a therapeutic trial is indicated to assess the response of vWF:RCo and FVIII. ${ }^{14,15}$ Its use in type $2 \mathrm{~B}$ is controversial, as the release of abnormal vWF multimers with an increased affinity for glycoprotein Ib leads to the transient appearance of thrombocytopenia, but there are a few reports where it has been used safely. ${ }^{16,17}$ DDAVP increases FVIII in Type $2 \mathrm{~N} v W D$ in most patients but the half-life is significantly reduced, ${ }^{18}$ therefore it is usually used in minor bleeding episodes, and vWF concentrate should be used to treat major bleeding or for invasive procedures.

DDAVP does not have any therapeutic use in type $3 \mathrm{vWD}$, and these patients must be treated with a vWF-containing concentrate.

The main limitation of using DDAVP is the development of tachyphylaxis, ie, the progressive reduction of responsiveness after repeated treatments. ${ }^{19}$ Hyponatremia, volume overload and subsequent seizures can be associated with DDAVP, due to repeated dosing within short intervals, therefore fluid restriction and serum sodium monitoring are advisable. ${ }^{20} \mathrm{As}$ there have been reports of myocardial infarction and stroke in elderly patients with established atherosclerotic disease, DDAVP should be used cautiously in such patients..$^{21,22}$

\section{von Willebrand factor-containing concentrate}

For those patients in whom DDAVP is ineffective or contraindicated, vWF and FVIII levels can be restored by infusion of concentrates, which may contain both FVIII and vWF or very high-purity vWF with minimum or no FVIII. ${ }^{30}$ When considering a vWF containing concentrate, there are minimal requirements: these products must have the same level of safety in eliminating the potential of blood-borne infections, and contain vWF that promotes adhesion and 
aggregation of platelets as well as transport and stabilization of FVIII. ${ }^{23}$ The pharmacokinetics and the efficacy of these products should be tested in patients with different types of vWD and be labeled with both vWF and FVIII potency. ${ }^{24}$

As vWF is a plasma-derived product, the risk of viral transmission has been minimized through the development of procedures for the viral inactivation of the plasma-derived concentrate. There is growing concern regarding the transmission of variant Creutzfeld Jacob Disease (vCJD) through blood products. In the UK there have been 4 cases of infection transmitted by blood transfusions from individuals who later developed $\mathrm{vCJD}^{25}$ and one case of a hemophilic who died of unrelated causes, but was found to have the vCJD prion protein in his spleen at post mortem. ${ }^{26}$ These concerns are fuelling the demand for alternative treatment options such as recombinant $\mathrm{vWF}$.

Important progress has been made in the standardization of vWF measurements in both plasma samples and concentrates which has been facilitated through the calibration of the WHO first International Standard for vWF:Ag and vWF:RCo. ${ }^{27}$

Studies demonstrate the hemostatic efficacy of a number of vWF-containing concentrates in the clinical settings of acute bleeds and surgical procedures, but there is no data to support the view that any concentrate has superior efficacy to any other. Commonly used products and their pharmacokinetic properties are shown in Table $1 .^{28-36}$

The amount of vWF-containing concentrate required to correct the hemostatic defect in VWD is dependent on the nature of a bleed, a patient's baseline vWF:RCo and FVIII and their subtype of vWD. In addition different types of surgery require different target vWF:RCo and FVIII levels. ${ }^{36}$

Patients vary in their response to infusions of vWFcontaining concentrate, therefore treatment regimens need to be individualized. Knowledge of an individual's pharmacokinetic response to infused $\mathrm{vWF}$-containing concentrate is a therapeutic advantage, and the previous demonstration of hemostatic efficacy correlates well with prospective therapy for surgery or management of acute bleeding episodes. ${ }^{37}$

The vWF:RCo and FVIII levels required for hemostasis have not been established in clinical trials. The general consensus however, for major operative procedures or significant bleeding, is that the vWF:RCo and FVIII should be raised to above $80 \mathrm{IU} / \mathrm{dL}$ and maintained above $50 \mathrm{IU} / \mathrm{dL}$ until hemostasis is secured and the FVIII level should be maintained above $50 \mathrm{IU} / \mathrm{dL}$ until wound healing is complete. Minor surgery may be performed successfully with a vWF: RCo and FVIII of approximately $50 \mathrm{IU} / \mathrm{dL} .{ }^{35,41-43}$
Sustained high levels of FVIII may increase the risk of venous thrombosis, ${ }^{38-40}$ therefore when repeated infusions of vWF:FVIII concentrates are necessary (eg, surgical procedures), the FVIII:C plasma levels should be measured daily to avoid levels in excess of $150 \mathrm{IU} / \mathrm{dL} .{ }^{40} \mathrm{As} v \mathrm{VF}: \mathrm{RCo}$ has a half life of 8-10 hours, and FVIII:C a half-life of 24-26 hours, both these levels should be monitored during prolonged treatment. Mannuci et $\mathrm{al}^{41}$ recommend primary thromboprophylaxis in vWD patients undergoing replacement therapy for major surgery and procedures at high risk of venous thromboembolism, at the same dosing schedules as for non-vWD patients.

All patients with vWD produce FVIII. In order to avoid excessively high FVIII levels after infusing vWF concentrates, a highly purified vWF (HP-vWF) concentrate containing very little FVIII has been developed. This differs from other vWF concentrates as the post-infusion levels of FVIII rise slowly, reaching a peak 6-12 hours post-infusion. Combined data from a number of trials for a HP-vWF concentrate (Wilfactin) has shown that clinical outcomes were excellent or good in $89 \%$ of patients with spontaneous bleeds, although 38\% of cases needed concomitant FVIII. Excellent or good efficacy was also observed in 95 elective surgical procedures without the need for prophylactic therapy with FVIII; however FVIII concentrate was required in 13 other patients needing surgery. ${ }^{42}$

A HP-vWF concentrate could potentially be utilized when prolonged infusion of product is needed, such as major elective surgery in those patients who are at a higher risk of developing thrombosis (old age, cancer, orthopedic surgery). Further studies are needed to identify the most appropriate patients and indications for use.

\section{Adjunctive treatments}

Management of mucosal bleeding, menorrhagia or prolonged oral bleeding after dental extraction involves the administration of antifibrinolytic amino acids (eg, tranexamic acid, epilson aminocapric acid). These agents inhibit the conversion of plasminogen to plasmin, inhibiting fibrinolysis and thereby helping to stabilize clots that have been formed. They can be administered either intravenously or orally, and can be used alone or as an adjunct to replacement therapy, to prevent or treat bleeding in mucosal tracts characterized by a rich fibrinolytic activity. ${ }^{44}$

These agents are also useful in administration along with replacement therapy during minor or major surgery involving mucosal surfaces. ${ }^{44}$ Tranexamic acid should be administered at a dose of $15-25 \mathrm{mg} / \mathrm{kg}$ orally (or $0.5-1 \mathrm{~g}$ 


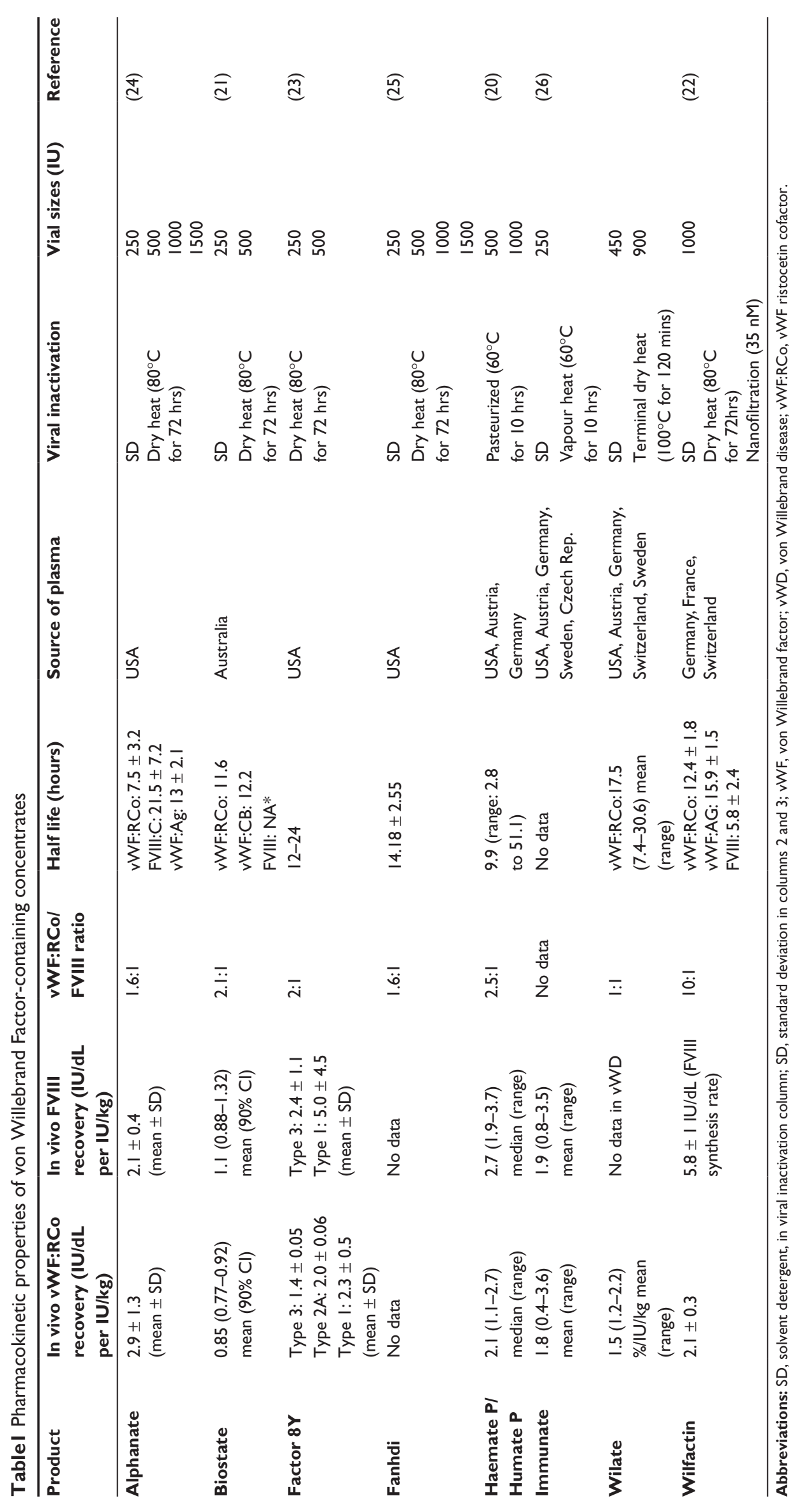


intravenously [IV]) every 8-12 hours and aminocaproic acid at a dose of 50-60 mg every 4-6 hours. These drugs are contraindicated in the management of urinary tract bleeding, due to the increased risk of intra-renal obstruction due to clot retention, in the renal pelvis or ureters. ${ }^{45}$

Topical Bovine thrombin or Fibrin sealant can be used as adjuncts to hemostasis in certain surgical situations especially in dental procedures. ${ }^{46}$ They are not useful in massive hemorrhage. Topical collagen sponges are also of use for the control of bleeding wounds. ${ }^{47}$

Platelets contain 10\%-15\% of total blood vWF, and platelet transfusions have been used successfully to treat bleeding in patients with vWD. ${ }^{48}$ Platelet transfusion should be considered in patients with type 3 or platelet-low vWD to control bleeding that is not responsive or poorly responsive to replacement therapy with vWF concentrate.

\section{Management of specific bleeding problems Dental treatment}

Treatment with DDAVP or concentrate is unnecessary for fillings performed under infiltration with local anesthetic; however treatment should be given if an inferior dental nerve block is used. ${ }^{35}$ In patients unsuitable for DDAVP, vWFcontaining concentrate should be used, aiming to increase the vWF:RCo and FVIII to $>50 \mathrm{IU} / \mathrm{dL} .{ }^{41}$ Oral antifibrinolytic agents should be commenced before treatment (along with local measures such as antifibrinolytic mouthwash) and continued for 7-10 days following extraction.

\section{Bleeding in women}

As mucocutaneous bleeding is the most common phenotype of bleeding in vWD, females with this disorder are frequently affected by reproductive tract bleeding and related complications. ${ }^{49}$

\section{Gynecological disorders}

Menorrhagia is common in women with vWD, affecting an estimated $80 \%-90 \%$ of patients. ${ }^{50}$ It may however, be a symptom of an underlying gynecological disorder, ${ }^{51}$ therefore it should be fully investigated. A study on behalf of the International Society of Thrombosis and Hemostasis (ISTH), demonstrated that up to a quarter of women required a hysterectomy for menorrhagia. ${ }^{52}$ Therefore, both medical and surgical treatments should be considered.

Both ovarian cysts and endometriosis occur more frequently in women with vWD compared with their normal counterparts. ${ }^{53}$ It is hypothesized that endometriosis is caused by retrograde menstruation and that vWD exacerbates and 'unmasks' this condition.

Medical therapies that have been used to control bleeding in vWD are the combined oral contraceptive pill (OCP), tranexamic acid, DDAVP and the levonorgesterel-releasing intrauterine system. ${ }^{54}$ In females who don't want to become pregnant, but who wish to have children in the future, the first choice of therapy should be the OCP (containing synthetic estrogen and a progestin). ${ }^{55}$ The progestin prevents ovulation and the synthetic estrogen prevents breakthrough bleeding. ${ }^{56}$ Studies have found that the OCP can increase levels of fibrinogen, FVIII and vWF. ${ }^{57-59}$

Intrauterine devices, such as the levonorgesterel-releasing intrauterine devices can be used as an alternative therapy in suitable candidates. This system is a progestin impregnated device, which is believed to reduce menstrual blood loss by opposing the estrogen induced growth of the endometrium. ${ }^{60}$

Alternative treatments in addition to medical therapy may have to be considered in difficult cases. This involves therapies such as endometrial ablation which has been proven to help control bleeding in women with vWD. ${ }^{61}$

\section{Pregnancy}

In normal pregnancy there is a progressive increase in FVIII and vWF levels from the second trimester onwards. ${ }^{62}$ This also occurs in women with vWD, which may explain the frequent improvement in minor bleeding manifestations during pregnancy. ${ }^{63-65}$

Most women with type 1 vWD have a progressive increase in vWF and FVIII, which may make the diagnosis difficult during pregnancy. ${ }^{66,67}$

In type 2 vWD, FVIII and vWF levels increase, but most studies show minimal or no increase in vWF activity levels and a persistently abnormal pattern of multimers reflecting the production of abnormal vWF. ${ }^{50,64,66,68}$ Most patients with type 3 vWD have no improvement in FVIII or vWF levels during pregnancy.

Theoretical concerns have been raised regarding the use of DDAVP in pregnancy due to the potential risks of placental insufficiency (as a result of vasoconstriction), an oxytocic effect and maternal and/or neonatal hyponatremia. ${ }^{69}$ No adverse effects were noted in association with DDAVP given in the second trimester in 32 women with vWD who underwent chorionic villous sampling or amniocentesis. ${ }^{70}$ Similarly, a systemic review of DDAVP in pregnant women with diabetes insipidus found no evidence of uterine stimulation, prematurity or low birth weight associated with the use of DDAVP antepartum. ${ }^{71}$ 
The vWF:RCo and FVIII levels for pregnant women with vWD should be measured at least once during the third trimester of pregnancy and within 10 days of the expected date of delivery. ${ }^{74}$ The risk of bleeding is minimal if FVIII and vWF:RCo are greater than $30 \mathrm{IU} / \mathrm{dL}$. These levels should also be measured for at least 2 weeks post-partum. The rapid falloff in vWF and FVIII levels that occurs post-partum, means that women are at an increased risk of post-partum hemorrhage (PPH), which is higher in type 2 and 3 disease and can persist for 7-21 days after delivery. ${ }^{73}$ A study from the Centers for Disease Control found that $59 \%$ of women with vWD experience a PPH compared with $21 \%$ of controls. ${ }^{60}$

Epidural anesthesia for pain relief may be considered with caution in patients with type I vWD, as the majority will have levels which have risen to within the normal range during pregnancy. ${ }^{42}$ Each individual patient's risk of bleeding, however, should be considered, depending on the degree of correction of FVIII and vWF level, and the anesthetist and obstetrician should be consulted. Epidural anesthesia is not recommended in type 2 and $3 \mathrm{vWD} .{ }^{42}$

In type $1 \mathrm{vWD}$, if the levels are lower than $30 \mathrm{IU} / \mathrm{dL}$ it may be necessary to administer DDAVP, which may be necessary for procedures during pregnancy or at the time of delivery.

In Type 2 and Type 3 vWD observation alone without treatment is sufficient if the FVIII $>50 \mathrm{IU} / \mathrm{dL}$. Dosing at delivery is usually 40-80 IU/kg vWF-concentrate and prophylaxis has usually been targeted to maintain vWF:RCO and FVIII $>50 \mathrm{IU} / \mathrm{dL}$ for at least 3-5 days postpartum. ${ }^{72}$

When the fetus is at risk of having type 2 or 3 vWD, invasive measures such as fetal scalp monitoring, rotational forceps, or ventouse delivery should be avoided. ${ }^{42}$ Irrespective of the mode of delivery, newborns at risk of type 2 or 3 vWD need to be tested for vWD using cord blood sampling and assessed to rule out an intra-cranial hemorrhage; early replacement therapy may be required depending on the nature of the delivery. Cord blood screening for type $1 \mathrm{vWD}$ will not give reliable results. ${ }^{42}$

In type $2 \mathrm{~B} v \mathrm{vW}$, increased production of mutant vWF may result in spontaneous platelet aggregation and severe thrombocytopenia during the third trimester. Platelet transfusion may therefore be required at delivery. ${ }^{48}$

\section{Acute bleeding}

For severe spontaneous or trauma-induced bleeding the vWF: RCo and FVIII levels should be increased to approximately $80 \mathrm{IU} / \mathrm{dL}$, until bleeding has been controlled. Adjunctive treatment, such as antifibrinolytic drugs and other local measures to achieve hemostasis should be considered, especially in mucosal bleeding. Lower levels of vWF:RCo and factor VIII are sufficient for minor bleeds.

\section{vWD and surgical procedures}

Patients with vWD undergoing surgical procedures, need regular assessment and correction of hemostasis pre and post-operatively. It is important to recognize that abnormal bleeding can be as a result of surgical bleeding, rather than inadequate hemostasis. The different subtypes of vWD have different product requirements, which are shown in Table 2 .

A vWF:RCo and FVIII of $50 \mathrm{IU} / \mathrm{dL}$ should be adequate for minor procedures, and often only one infusion is required. Antifibrinolytics can be administered both pre and post operatively to assist with hemostasis.

An infusion of a vWF- concentrate calculated to increase the vWF:RCo level to $80-100 \mathrm{IU} / \mathrm{dL}$ at the time of surgery is recommended and this level should be maintained above $50 \mathrm{IU} / \mathrm{dL}$ until hemostasis is secure. ${ }^{35,41}$ The FVIII should be raised to approximately $100 \mathrm{IU} / \mathrm{dL}$ perioperatively and maintained above $50 \mathrm{IU} / \mathrm{dL}$ until wound healing is complete. This requires regular monitoring of both $\mathrm{VWF}$ :RCo and FVIII.

$\mathrm{HP}-\mathrm{vWF}$ concentrates are infused at a dose of $50 \mathrm{IU} / \mathrm{kg}$ vWF:RCo, 12-24 hours before surgery if the FVIII is less than $60 \mathrm{IU} / \mathrm{dL}$. A further dose is given 1 hour before surgery and subsequent infusions are given to maintain a vWF:RCo level $>60 \mathrm{IU} / \mathrm{dL}$ and a FVIII level $>40 \mathrm{IU} / \mathrm{dL}$. Unscheduled surgery is treated with HP-vWF concentrate at $50 \mathrm{IU} / \mathrm{kg}$ and FVIII to the same target levels. ${ }^{72}$

The risk of VTE should be assessed in patients undergoing major surgery, who receive vWF-containing concentrates, and therefore high levels of FVIII should be avoided, and thromboprophylaxis considered. ${ }^{41}$

A summary of the initial dosing recommendations for vWF concentrate replacement for prevention or management of bleeding is shown in Table $3 .^{49}$

Table 2 Product types required, depending on sub-type of vWD, in minor and major surgical procedures

\begin{tabular}{|c|c|c|}
\hline $\begin{array}{l}\text { vWD } \\
\text { subtype }\end{array}$ & $\begin{array}{l}\text { Minor surgical } \\
\text { procedures treatment }\end{array}$ & $\begin{array}{l}\text { Major surgical } \\
\text { procedure treatment }\end{array}$ \\
\hline Type I & DDAVP & vWF concentrate \\
\hline Type 2A/2M & DDAVP & vWF concentrate \\
\hline Type 2B & vWF concentrate & vWF concentrate \\
\hline Type 2N & DDAVP & vWF concentrate \\
\hline Type 3 & vWF concentrate & vWF concentrate \\
\hline
\end{tabular}

Note: Antifibrinolytic therapy, both pre and post-operatively (until wound healing achieved) should be used as an adjunct in both minor and major surgical procedures. Abbreviations: DDAVP, desmopressin (I-desamino-8-D-arginine vasopressin); vWF, von Willebrand Factor; vWD, von Willebrand Disease. 
Table 3 A summary of the initial dosing recommendations for vWF concentrate replacement for prevention or management of bleeding

\begin{tabular}{lll}
\hline & Major surgery & Minor surgery \\
\hline Loading dose & $40-60 \mathrm{IU} / \mathrm{kg}$ & $30-60 \mathrm{IU} / \mathrm{kg}$ \\
Maintenance dose & $20-40 \mathrm{IU} / \mathrm{kg}$ & $20-40 \mathrm{IU} / \mathrm{kg}$ \\
& every 8-24 hours & every I2-48 hours \\
Monitoring & Daily trough and peak & Trough and peak \\
& vWF:RCo and FVIII & vWF:RCo and \\
& & FVIII at least once \\
Theraputic goal & vWF:RCo and FVIII & Trough vWF:RCo and \\
& trough $>50 \mathrm{IU} / \mathrm{dL}$ & FVIII $>50 \mathrm{IU} / \mathrm{dL}$ \\
& for 7-I4 days & for 3-5 days \\
\hline
\end{tabular}

Abbreviations: FVIII, Factor VIII; vWF:RCo, von Willebrand Factor ristocetin cofactor.

\section{Prophylaxis}

The most prominent symptom in vWD is that of mucosal bleeding (eg, epistaxis, gastrointestinal bleeding and menorrhagia). Hemarthrosis (joint bleeding), and spontaneous muscular bleeding, resembling those of hemophilia, may occur rarely, particularly in patients with a secondary deficiency of FVIII. It has been reported, in some series that $37 \%-45 \%$ of subjects with type $3 \mathrm{vWD}$ had experienced at least one episode of hemarthrosis. ${ }^{73,74}$

The first data on the usefulness of prophylaxis was obtained from Sweden, where retrospective data from 35 patients demonstrated that vWF/FVIII infusions administered at least once weekly were found to substantially reduce mucosal bleeding and hemarthrosis and there was no evidence of progression to arthropathy. ${ }^{75}$ There is a potential role for prophylaxis in vWD.

According to a survey of 74 centers in Europe and North America approximately three-quarters of patients receiving prophylaxis have type $3 \mathrm{vWD}$. Indications for prophylaxis include recurrent hemarthrosis (14\%), epistaxis (23\%), gastrointestinal bleeding (14\%), and menorrhagia (5\%). ${ }^{76}$

The optimum prophylactic regimen for vWD has not yet been established, and it is likely that it may not need to be administered as regularly as prophylaxis for patients with severe hemophilia A. Retrospective data from 120 patients enrolled on an Italian national registry has suggested that long-term secondary prophylaxis with vWF/FVIII (40 IU/kg) prevents or reduces bleeding in vWD patients with a history of recurrent hemorrhage. ${ }^{77}$ There is now a prospective randomized study comparing on-demand and prophylactic treatment, and the results of these studies will help better define the role of prophylaxis in patients with von Willebrand disease, and also provide more data on the optimum treatment regimes.

\section{The future}

The management of vWD has changed over the past 15 years, and treatments such as DDAVP, vWF containing concentrate are well established. The role of secondary prophylaxis needs to be further defined. The development of recombinant vWF currently undergoing phase 1 studies in type $3 \mathrm{vWD}$ is likely to offer further treatment options in the future. ${ }^{78}$ Alternative therapy such as gene therapy, which is attempting to partially correct $v W F$ defects, may change management in the future in patients with type $3 \mathrm{vWD} .{ }^{49}$

\section{Disclosure}

The authors declare that there are no potential conflicts of interest in this work.

\section{References}

1. Rodeghiero F, Castaman G, Dini E. Epidemiological investigation of the prevalence of von Willebrand's disease. Blood. 1987;69(2): 454-459.

2. Manusco DJ, TuleyEA, Westfield LA, et al. Structure of the gene for human von Willebrand Factor. J Biol Chem. 1989;264(33):19519-19527.

3. Sadler JE. A revised classification of von Willebrand disease. Thromb Haemost. 1994;71(4):520-525.

4. Sadler JE, Budde U, Eikenboom JC, et al. Update on the pathophysiology and classification of von Willebrand disease. J Thromb Haemost. 2006;4(10):2103-2114.

5. Kaufman JE, Oksche A, Wollheim CB, Gunther G, Rosenthal W, Vischer UM. Vasopressin induced von Willebrand factor secretion from endothelial cells involves V2 receptors and cAMP. J Clin Invest. 2000;106(1):107-116.

6. Mannuci PM, Albery M, Nilsson IM, Robertson B. Mechanism of plasminogen activation and factor VIII increase after vasoactive drugs. Br J Haematol. 1975;30(1):81-93.

7. Mannuci PM, Canciani MT, Rota L, Donovan BS. Response of factor VIII/von Willebrand factor to DDAVP in healthy subjects and patients with haemophilia A and von Willebrand disease. Br J Haematol. 1981; 47(2):283-293.

8. Rodeghero F, Castaman G, Mannuci PM. Prospective multicentre study on subcutaneous concentrated desmopressin for home treatment of patients with von Willebrand disease and mild or moderate haemophilia A. Thromb Haemost. 1996;76(5):692-696.

9. Smith TJ, Gill JC, Ambruso DR, Hathaway WE. Hyponatraemia and seizures in young children given DDAVP. Am J Hematol. 1989; 31(3):199-202.

10. Mannucci PM. Desmopressin (DDAVP) in the treatment of bleeding disorders: the first 20 years. Blood. 1997;90(7):2515-2521.

11. Federici AB, Mazurier C, Berntorp E, et al. Biologic response to desmopressin in patients with severe type 1 and type 2 von Willebrand disease: results of a multicenter European study. Blood. 2004; 103(6):2032-2038.

12. Castaman G, Lethagen S, Federici AB, et al. Response to desmopressin is influenced by the genotype and phenotype in type 1 von Willebrand disease (vWD): results from the European Study MCMDM-1vWD. Blood. 2008;111(7):3531-3539.

13. Brown SA, Eldridge A, Collins PW, Bowen DJ. Increased clearance of von Willebrand factor antigen post-DDAVP in type 1 von Willebrand disease: is it a potential pathogenic process? J Thromb Haemost. 2003;1(8):1714-1717.

14. Casanato A, Pontara E, Sartorello F, et al. Reduced von Willebrand factor survival in type Vincenza von Willebrand disease. Blood. 2002;99(1):180-184. 
15. Michiels JJ, van de Velde A, van Vliet HH, van der Planken M, Schroyens W, Berneman Z. Response of von Willebrand factor parameters to desmopressin in patients with type 1 and type 2 congenital von Willebrand disease: diagnostic and therapeutic implications. Semin Thromb Hemost. 2002;28(2):111-132.

16. Gralnick HR, Williams SB, McKeown LP, et al. DDAVP in type IIa von Willebrand's disease. Blood. 1986;67(2):465-468.

17. Casonato A, Pontara E, Dannhaeuser D, et al. Re-evaluation of the therapeutic efficacy of DDAVP in type IIB von Willebrand's disease. Blood Coagul Fibrinolysis. 1994;5(6):959-964.

18. Fowler WE, Berkowitz LR, Roberts HR. DDAVP for type IIB von Willebrand disease. Blood. 1989;74(5):1859-1860.

19. Mazurier C, Gaucher C, Jorieux S, Goudemand M. Biological effect of desmopressin in eight patients with type $2 \mathrm{~N}$ ('Normandy') von Willebrand disease. Collaborative Group. Br J Haematol. 1994;88(4):849-854.

20. Mannucci PM, Bettega D, Cattanco M. Patterns of development of tachyphylaxis in patients with haemophilia and von Willebrand disease after repeated doses of desmopressin (DDAVP). Br J Haematol. 1992; 82(1):87-93.

21. Byrnes JJ, Lacarda A, Moake JL. Thrombosis following desmopressin for uremic bleeding. Am J Hematol. 1988;28(1):63-65.

22. Bond L, Bevan D. Myocardial Infarction in a patient with haemophilia treated with DDAVP. N Eng J Med. 1988;318(2):121.

23. Mannucci PM. Treatment of von Willebrand's Disease. $N$ Engl J Med. 2004;351(7):683-694.

24. Mazurier C. Composition, quality control and labeling of plasmaderived products for the treatment of von Willebrand disease. Semin Thromb Hemost. 2006;32(5):529-536.

25. Hewitt PE, Llewelyn CA, MacKenzie J, Will RG. Creutzfeld-Jacob Disease and blood transfusion : results of the UK Transfusion Medicine Epidemiological Review Study. Vox Sang. 2006;91(3):221-230.

26. Health Protection Report, 20 February 2009, Volume 3, No. 7.

27. Hubbard AR. Von Willebrand factor standards for plasma and concentrate testing. Semin Thromb Hemost. 2006;32(5):522-528.

28. Dobrkovska A, Krzensk U, Chediak JR. Pharmacokinetics, efficacy and safety of Humate-P in von Willebrand disease. Haemophilia. 1998; 4 Suppl 3:33-39.

29. Favaloro EJ, Lloyd J, Roswell J, et al. Comparison of the pharmacokinetics of two von Willebrand factor concentrates [Biostate and AHF (High Purity)] in people with von Willebrand disorder. A randomised crossover, multi-centre study. Thromb Haemost. 2007;97(6):922-930.

30. Goudemand J, Scharrer I, Berntorp E, et al. Pharmacokinetic studies on Wilfactin, a von Willebrand factor concentrate with a low factor VIII content treated with three virus-inactivation/removal methods. J Thromb Haemost. 2005;3(10):2219-2227.

31. Lubetsky A, Martinowitz U, Luboshitz J, et al. Efficacy and safety of a factor VIII- von Willebrand concentrate 8Y: stability, bacteriological safety, pharmacokinetic analysis and clinical experience. Haemophilia. 2002;8(5):622-628.

32. Mannucci, PM, Chediak, J, Hanna W; for Alphanate Study Group. Treatment of von Willebrand disease with a high-purity factor VIII/ von Willebrand factor concentrate: a prospective, multicenter study. Blood. 2002;99(2):450-456.

33. Federici AB, Baudo F, Caracciolo C, et al. Clinical efficacy of highly purified, doubly virus-inactivated factor VIII/von Willebrand factor concentrate (Fanhdi) in the treatment of von Willebrand disease: a retrospective clinical study. Haemophilia. 2002;8(6):761-767.

34. Bello IF, Yuste VJ, Molina MQ, Navarro FH. Fanhdi, efficacy and safety in von Willebrand's disease: prospective international study results. Haemophilia. 2007;13 Suppl 5:25-32.

35. Pasi KJ, Collins PW, Keeling DM, et al. Management of con Willebrand disease: guidelines from the UK Haemophilia Centre Doctors' Organization. Haemophilia. 2004;10(3):218-231.

36. Collins PW. Treatment of von Willebrand disease: therapeutic concentrates. In: Lee CA, Berntorp EE, Hoots WK, editors. Textbook of Hemophilia. Oxford: Blackwell Publishing; 2010:322.
37. Lethagen S, Kyrle PA, Castaman G; for Haemate P Surgical Study Group. Von Willebrand factor/factor VIII concentrate (Haemate P) dosing based on pharmacokinetics: a prospective multicentre trial in elective surgery. J Thromb Haemost. 2007;5(7):1420-1430.

38. Makris M, Colvin B, Gupta V, Shields ML, Smith MP. Venous thrombosis following the use of intermediate purity FVIII concentrate to treat patients with von Willebrand's disease. Thromb Haemostat. 2002; 88(3):387-388.

39. Mannucci PM. Venous thromboembolism in von Willebrand disease. Thromb Haemost. 2002;88(3):378-379.

40. Kyrle PA, Minar E, Hirschl M, et al. High plasma levels of factor VIII and the risk of recurrent venous thromboembolism. NEngl J Med. 2000; 343(7):457-462.

41. Mannuci PM, Franchini M, Castaman G; for Italian Association of Hemophilia Centers. Evidence-based recommendations on the treatment of von Willebrand disease in Italy. Blood Transfus. 2009; $7(2): 117-126$

42. Federici AB, Castaman G, Mannucci PM; for Italian Association of Hemophilia Centres (AICE). Evidence-based recommendations on the treatment of von Willebrand disease in Italy. Haemophilia. 2002; 8(5):607-621.

43. Lillicrap D, Poon MC, Walker I; for Association of Hemophilia Clinic Directors of Canada. Efficacy and safety of the factor VIII/von Willebrand factor concentrate, haemate-P/humate-P: ristocetin cofactor unit dosing in patients with von Willebrand disease. JThromb Haemost. 2002;87(2):224-230.

44. Mannucci. Hemostatic Drugs. N Engl J Med. 1998;339(4):245-253.

45. Lingardh G, Anderson L. Clot retention in the kidney as a probable cause of anuria during treatment of haematuria with epilson-aminocapric acid. Acta Med Scand. 1966;180(4):469-473.

46. Zwischenberger JB, Brunston RL Jr, Swann JR, Conti VR. Comparison of two topical collagen-based hemostatic sponges during cardiothoracic procedures. J Invest Surg. 1999;12(2):101-106.

47. Castillo R, Monteagudo J, Escolar G, et al. Hemostatic effect of normal platelet transfusion in severe von Willebrand disease patients. Blood. 1991;77(9):1901-1905.

48. Greer IA, Lowe GD, Walker JJ, Forbes CD. Haemorrhagic problems in obstetrics and gynaecology in patients with congenital coagulopathies. Br J Obstet Gynaecol. 1991;98(9):909-918.

49. Nichols WL, Hultin MB, James AH, et al. Von Willebrand disease (vWD): evidence-based diagnosis and management guidelines, the National Heart, Lung and Blood institute (NHLBI) Expert Panel report (USA). Haemophilia. 2008;14(2):171-232.

50. Chuong CJ, Brenner PF. Management of abnormal uterine bleeding. Am J Obstet Gynecol. 1996;175(3 Pt 2):787-792.

51. Foster PA. The reproductive health of women with von Willebrand disease unresponsive to DDAVP : results of an international survery on behalf of the Subcommittee on von Willebrand Factor of the Scientific and Standarization committee of the ISTH. Thromb Haemost. 1995;74(2):784-790.

52. Kiratava A, Drews C, Lally C, Dilley A, Evatt B. Medical, reproductive and psychosocial experiences of women diagnosed with von Willebrand's disease receiving care in haemophilia treatment centres: a case- control study. Haemophilia. 2003;9(3):292-297.

53. Lahteenmaki P, Haukkamaa M, Puolakka J, et al. Open randomised study of use of levonorgestrel releasing intrauterine system as alternative to hysterectomy. BMJ. 1998;316(7138):1122-1126.

54. Pettiti DB. Clinical practice: combination estrogen-progestin oral contraceptives. N Engl J Med. 2003;349(15):1443-1450.

55. Rosendaal FR, Helmerhorst FM, Vandenbroucke JP. Female hormones and thrombosis. Arterioscler Thromb Vasc Biol. 2002;22(2):201-210.

56. Beller FK, Ebert C. Effects of oral contraceptives on blood coagulation: a review. Obstet Gynecol Surv. 1985;40(7):425-436.

57. Kadir RA, Economides DL, Sabin CA, Owens D, Lee CA. Variations in coagulation factors in women: effects of age, ethnicity, menstrual cycle and combined oral contraceptive. Thromb Haemost. 1999;82(5):1456-1461. 
58. Middeldorp S, Meijers JV, van den Ende AE, et al. Effects on coagulation of levonorgesterel- and desogesterel-containing low dose oral contraceptives: a cross-over study. Thromb Haemost. 2000(1);84:4-8.

59. Davis A, Godwin A, Lippman J, Olson W, Kafrissen M. Triphasic norgestimate-ethinyl estradiol for treating dysfunctional uterine bleeding. Obstet Gynecol. 2000;96(6):913-920.

60. Sharp HT. Assessment of new technology in the treatment of idiopathic menorrhagia and uterine leiomyomata. Obstet Gynecol. 2006; 108(4):990-1003.

61. Sie P, Caron C, Azam J, Goudemand J, et al. Reassessment of von Willebrand factor (vWF), vWF propetide, factor VIII. C and plasminogen activator inhibitors 1 and 2 during normal pregnancy. Br J Haematol. 2003;121(6):897-903.

62. Kadir RA, Lee CA, Sabin CA, Pollard D, Economides DL. Pregnancy in women with von Willebrand's disease or factor XI deficiency. $\mathrm{Br} J$ Obstet Gynaecol. 1998;105(3):314-321.

63. Ramsahoye BH, Davies SV, Dasani H, Rearson JF. Obstetric management in von Willebrands disease: a report of 24 pregnancies and review of the literature. Haemophilia. 1995;1(2):140-144.

64. Alperin JB. Estrogens and surgery in women with von Willebrand's disease. Am J Med. 1982;73(3):367-371.

65. Conti M, Mari D, Conti E, Muggiasca ML, Mannucci PM. Pregnancy in women with different types of von Willebrand disease. Obstet Gynecol. 1986;68(2):282-285.

66. Chediak JR, Alban GM, Maxey B. von Willebrands disease and pregnancy: management during delivery and outcome of offspring. Am J Obstet Gynaecol. 1986;155(3):618-624.

67. Casonato A, Sartori MT, Bertomoro A, Fede T, Vasoin F, Girolami A. Pregnancy-induced worsening of thrombocytopenia in a patient with type IIB von Willebrands disease. Blood Coagul Fibrinolysis. 1991; 2(1):33-40.

68. Kouides PA. Obstetric and gynaecological aspects of von Willebrand disease. Best Pract Res Clin Haematol. 2001;14(2):281-299.

69. Ray JG. DDAVP use during pregnancy: an analysis of its safety for mother and child. Obstet Gynecol Surv. 1998;53(7):450-455.
70. Mannucci, et al. Use of desmopressin (DDAVP) during early pregnancy in factor VIII deficient women. Blood. 2005;105(8):3382.

71. Dahlman T, Hellgren M, Blomback M. Changes in blood coagulation and fibrinolysis in the normal puerperium. Gynecol Obstet Invest. 1985; 20(1):37-44.

72. Borel-Derlon A, Federici AB, Roussel-Robert V, et al. Treatment of severe von Willebrand disease with a high-purity von Willebrand factor concentrate (Wilfactin): a prospective study of 50 patients. J Thromb Haemost. 2007;5(6):1115-1124.

73. Lak M, Peyvandi F, Mannucci P. Clinical manifestations and complications of childbirth and replacement therapy in 385 Iranian patients with type 3 von Willebrand disease. Haemophilia. 2000;111(4): 1236-1239.

74. Federici AB. Clinical diagnosis of von Willebrand disease. Haemophilia. 2004;10 Suppl 4:169-176.

75. Berntorp E, Petrini P. Long-term prophylaxis in von Willebrand disease. Blood Coagul Fibrinolysis. 2005;16 Suppl 1:S23-S26.

76. Berntorp E, Abshire T; for von Willebrand Disease Prophylaxis Network Steering Committee. The von Willebrand disease prophylaxis network: exploring a treatment concept. J Throm Haemost. 2006; 4:2511-2512.

77. Federici AB, Barillari G, Zanon E, et al. Efficacy and safety of highly purified doubly virus inactivated vWF/FVIII concentrates in the management of inherited von Willebrand disease: results from the retrospective Italian study on 120 cases. Poster presented: 28th World Federation of Hematology Congress, Istanbul, Turkey, 1-5 June 2008, abstract 713

78. ClinicalTrials.gov (homepage on the Internet). Pharmacokinetic, Safety and Tolerability Study of Recombinant von Willebrand factor/ Recombinant Factor VIII Complex in Type 3 von Willebrand Disease. [Updated February 23, 2011]. Available from http://clinicaltrials.gov/ ct2/show/NCT00816660/accessed February 23, 2011.

\section{Publish your work in this journal}

The Journal of Blood Medicine is an international, peer-reviewed, open access, online journal publishing laboratory, experimental and clinical aspects of all topics pertaining to blood based medicine including but not limited to: Transfusion Medicine; Blood collection, Donor issues, Transmittable diseases, and Blood banking logistics; Immunohematology; Artificial and alternative

\section{Dovepress}

blood based therapeutics; Hematology; Biotechnology/nanotechnology of blood related medicine; Legal aspects of blood medicine; Historical perspectives. The manuscript management system is completely online and includes a very quick and fair peer-review system. Visit http://www.dovepress.com/ testimonials.php to read real quotes from published authors. 